\title{
AVALIAÇÃO SOBRE O TRATAMENTO CONCEDIDO AOS CONTEÚDOS DE GEOMORFOLOGIA NOS LIVROS DIDÁTICOS DA EDUCAÇÃO BÁSICA BRASILEIRA.
}

\author{
José Mario L. Martins Costa ${ }^{(a)}$, Priscila Daiane Pavan ${ }^{(b)}$ \\ (a) Prof. Assistente do Curso de Geografia da Universidade Federal da Fronteira Sul/RS, jose.costa@uffs.edu.br \\ Doutorando em Geografia pela Universidade Federal do Rio Grande do Sul. \\ (b) Licencianda em Geografia, Universidade Federal da Fronteira Sul/RS, prisciladpavan@ @otmail.com
}

EIXO: GEOGRAFIA FÍSICA: CURRÍCULO, FORMAÇÃO E PRÁTICAS DE ENSINO

\begin{abstract}
Resumo
O presente artigo resulta da aplicação de uma prática pedagógica junto à alunos licenciando em Geografia, visando avaliar o modo pelo qual os conteúdos de geomorfologia estão sendo apresentados e trabalhados nos livros didáticos dos Ensinos Fundamental e Médio. De forma geral, foi observado que, apesar das variações para cada obra inerentes ao nível de conhecimento dos autores e á importância que conferem ao ensino de geomorfologia, as abordagens utilizadas ainda não atendem satisfatoriamente ao conhecimento necessário e essencial à este ramo geográfico. De outra forma, o reforço no estudo das questões ambientais surgidas com as atividades antrópicas parecem ter valorizado o estudo do relevo e a importância em integra-lo aos demais temas trabalhados na geografia física e humana dentro da realidade dos educandos, sendo constatada tal tendência com maior frequência nas obras mais recentes.
\end{abstract}

Palavras chave: Ensino de geomorfologia; Livros didáticos.

\section{Introdução.}

Os conteúdos de geomorfologia são trabalhados na Educação Básica através do ensino de Geografia, a qual, além de trabalhar com uma enorme gama de fenômenos naturais e sociais, também encarrega-se de abordar agentes, processos, e formas de relevo distintos que modelam paisagens diversificadas no globo terrestre (ALBUQUERQUE e SOBRINHO, 2007).

Na concepção de Batista e Souza (2012), a geomorfologia, assim como os demais conteúdos de geografia física, é ensinado nas escolas, porém, os alunos não conseguem perceber a importância desta disciplina. Conforme os autores, a causa do problema pode provir dos livros didáticos e da própria formação do professor. Pare este último, o domínio da disciplina torna-se essencial para as explicações do conteúdo aos alunos, mas, como isto nem sempre ocorre, sucede uma maior ênfase a outros conteúdos mais simples em detrimento da geomorfologia.

Esta mesma percepção é compartilhada por Alencar, Nascimento e Guimarães (2012), que compreendem uma subvalorização da importância dos estudos e temas relacionados à geomorfologia e à dinâmica da 
Terra pela falta de domínio e preparo dos profissionais em transmitir estes conhecimentos, sendo, mormente, tratados de modo superficial e desconectado da realidade do educando.

Outrossim, o mesmo ocorre com a questão do livro didático na visão de Batista e Souza (2012). Visto como um instrumento essencial ao aprendizado dos alunos, inclusive para o ensino de geomorfologia, este ramo da geografia muitas vezes não é apresentado de forma adequada naquelas obras, ou não tem oferecidos todos os conteúdos essenciais para o educando.

Ainda conforme Batista e Souza (2012), os alunos, principalmente do Ensino Fundamental, precisam de uma linguagem mais lúdica e voltada para a sua realidade vivida. É importante que percebam a presença da geomorfologia em suas vidas ou em seu dia a dia. Deve existir o esclarecimento do papel exercido pelo relevo na totalidade do conhecimento, e a compreenção da sua aplicabilidade no mundo real (OLIVEIRA e NUNES, 2009).

Para superar a problemática em trabalhar os conteúdos de geomorfologia nas escolas, Oliveira, Amorim e Santos (2006) sugerem trata-los como temas transversais dentro do próprio estudo de geografia, buscando relacionar o modelado terrestre com a litologia, a hidrografia, a vegetação, o clima, o solo e, principalmente, a distribuição da população. Neste viés, Oliveira e Nunes (2009) indicam dois significados do relevo trabalhados no contexto ideológico, sendo um no sentido histórico e político (o relevo utilizado como palco de base territorial), e o outro na condição de externalização, através dos riscos socioambientais associados.

Da mesma forma, a emersão da questão ambiental, derivado das ações antrópicas inadequadas sobre o ambiente rural ou urbano, tem provocado um ganho de importância nos estudos dos processos e questões da natureza, sendo cada vez mais necessária a incorporação da análise do relevo nas diretrizes de organização do espaço e de planejamento ambiental (OLIVEIRA e NUNES, 2009; FURIM, 2012). Isto denoda a importância em associar e correlacionar as dinâmicas do relevo com as diversas atividades desenvolvidas pelo homem no ensino de geomorfologia (BATISTA e SOUSA, 2012).

Este apelo suscitado pelas questões ambientais promove a necessidade de integração de saberes não apenas dentro da própria geografia, mas também entre os demais ramos de conhecimento das demais disciplinas trabalhadas nas escolas. Entretanto, poucas são as tentativas em realizar estes diálogos nos conteúdos dos livros didáticos, e, os poucos que se arriscam nesta tendência raramente obtem êxito em suas iniciativas, permanecendo o tradicional modelo de informações fragmentadas e compartimentadas apresentadas de formas justapostas para simular uma possível integração. 
De forma geral, os autores que trabalham com o tema, ou seja, o ensino de geomorfologia nas escolas, parecem concordar que existe uma deficiência responsável pelo insucesso deste processo nas salas de aula, destacando-se, entre outros fatores, a formação do professor, as abordagens dos livros didáticos e o direcionamento dos conteúdos no trabalho com a disciplina.

Neste âmbito de análise, o presente artigo resulta do projeto de pesquisa realizado junto às turmas da disciplina de Geomorfologia do Curso de Licenciatura em Geografia da Universidade Federal da Fronteira Sul (Campus Erechim/RS), mediante práticas pedagógicas aplicadas àquelas primeiras, no intuito de avaliar como os conteúdos de geomorfologia estão sendo apresentados e trabalhados pelos livros didáticos empregados nas escolas de Educação Básica brasileiras (Ensino Fundamental e Ensino Médio), para o aprendizado não apenas dos conceitos e processos inerentes à compreensão daquele ramo de estudo em geografia, mas também da sua importância, da aplicabilidade prática na sociedade e da percepção do papel que exerce nas paisagens que integram a vida dos estudantes cotidianamente.

\section{Metodologia.}

O presente trabalho deriva de um projeto de pesquisa que envolve uma atividade acadêmica desenvolvida na disciplina de Geomorfologia junto com turmas do Curso de Licenciatura em Geografia da Universidade Federal da Fronteira Sul - Campus Erechim/RS, aplicada no período de 2014 a 2016.

A referida atividade consistiu na divisão das turmas em grupos, cabendo a cada qual efetuar a análise de pelo menos três livros didáticos de geografia utilizados no Ensino Básico, e avaliar os conhecimentos de geomorfologia contidos nos mesmos. Nesta análise deveria constar, minimamente, a identificação dos livros abordados e dos seus respectivos autores, bem como os conteúdos geomorfológicos trabalhados em cada obra e uma avaliação crítica dos mesmos, indicando os seus pontos positivos e eventuais deficiências no que tange: ao modo e ao nível de importância com os quais são trabalhados os temas geomorfológicos; a clareza das explicações, a abordagem didática e a linguagem utilizada nos elementos textuais; e, os recursos visuais utilizados (imagens, fotos, mapas, tabelas, quadros, gráficos, etc.) considerando a consonância dos mesmos em relação aos textos explicativos e aos temas de estudo.

Os resultados das análises foram apresentados pelos grupos em sala de aula, e debatidos entre os alunos de cada turma, objetivando uma comparação coletiva entre a totalidade de livros trabalhados pelas turmas, o modo como o ensino de geomorfologia está sendo abordado nas obras didáticas, e o compartilhamento dos títulos mais indicados ao direcionamento do ensino de geomorfologia nas classes do Educação Básica para uso dos futuros professores. 
Após a etapa de atividade didática, com fins de prática pedagógica com as turmas, foi o momento de tabulação e análise das informações coletadas e trabalhadas pelos alunos, dando-se no âmbito do projeto de pesquisa supra mencionado. A partir deste processo, buscou-se agrupar e analisar qualitativamente as informações levantadas pelos alunos, para fazer uma súmula de como os temas de geomorfologia estão sendo tratados nos livros didáticos, e como isto pode refletir no ensino deste ramo geográfico nas escolas de Educação Básica.

\section{Resultados.}

Durante o período de três anos em que foi aplicado a prática em questão, seguindo sempre o mesmo procedimento de trabalho, foram analisados uma totalidade de 26 títulos, sendo 12 direcionados ao Ensino Médio e 14 ao Ensino Fundamental. Não foram contabilizados neste número os títulos repetidos e em edições diferentes que foram analisados por grupos distintos, mas foram consideradas as análises feitas para cada qual, sendo efetuadas comparações entre as edições dos títulos de respectividade (de modo geral, não houveram alterações significativas para o ensino de geomorfologia de uma edição para outra nas mesmas obras).

Os títulos analisados remetem às edições publicadas no período entre os anos de 2002 e 2015, havendo maior concentração de obras dos últimos sete anos. Com isto, tem-se um panorama relativamente recente do modo pelo qual os conteúdos direcionados ao estudo em geomorfologia estão sendo abordados nos livros didáticos utilizados no Ensino Básico das escolas brasileiras.

De modo genérico, foi observada uma estruturação comum a grande parte das obras no que tange a organização e apresentação dos conteúdos sobre o estudo do relevo. Ainda que com algumas variações de obra para obra, há uma sequência que elenca os conteúdos sumariamente em: influências endógenas, influências exógenas, formas sobre a superfície terrestre, e relevo do Brasil. Embora tal estrutra de conteúdos seja, de fato, minimamente prevista curricularmente para o ensino de geomorfologia, e essencial para a sua compreenção, o que torna diferencial uma obra da outra é o modo como os assuntos são trabalhados.

Verifica-se que em grande parte das obras, os temas relacionados à dinâmica da Terra, mais associados aos processos geológicos, não apenas se confundem com as explicações relativas à geomorfologia, mas também tornam-se predominantes. Há uma maior valorização da abordagem geológica na explicação das formas superficiais da Terra, e pouca associação com os processos geomorfológicos em si. O referencial teórico para muitos autores ainda é balizado no modelo Davisiano, sendo frequentemente observada a descrição das formas a partir do ciclo geográfico, incorporando fases de juventude, maturidade e 
senilidade. Não raras vezes, o indicativo das formas do relevo dá-se com maior ênfase dentro do contexto estrutural, havendo pouca integração com as sucessões climáticas que influenciaram nos modelados das formas e na dinâmica natural das diversas paisagens terrestres ao longo do tempo geológico. Do mesmo modo, pouca interação há na explicação das compartimentações do relevo e nas sucessões das formas por ordem de grandeza, incluindo as feições em nível de detalhamento que podem ser trabalhadas a partir de uma abordagem processo-forma.

Acredita-se que parte das questões mencionadas decorra da falta de percepção entre a articulação de escalas espaciais (e mesmo temporais), e os conjuntos de formas observadas na superfície terrestre. Mormente, as formas de relevo mencionadas nos livros didáticos são aquelas relacionadas a pequenas escalas, em níveis continentais ou macroregionais, e, quando buscam mencionar formas em escalas espaciais maiores, o fazem citando-as apenas por suas denominações sem que se explique as suas origens ou as suas relações com conjuntos de formas maiores.

Do mesmo modo em que muitas das obras analisadas não efetuam uma associação escalar entre as formas, bem como a explicação genética, evolutiva e morfodinâmica das mesmas, observa-se que faz-se pouca associação do relevo com os demais elementos naturais, integrando-o com a hidrologia, a vegetação, os solos, e o clima. Da mesma forma, as análises dos alunos demonstraram que ainda existe uma forte dificuldade em integrar os conteúdos de ensino de geomorfologia com a dinâmica das atividades humanas, aparecendo de forma tímida em alguns títulos, e sequer sendo citado em outros. Felizmente, há uma tendência de mudança neste sentido, principalmente pela emersão das questões ambientais que tem valorizado as abordagens de estudo do relevo. Algumas obras já estão se direcionando neste sentido, e foi verificado que algumas destas já trazem integrada a relação com as atividades humanas nos estudos referentes ao relevo, demonstrando a sua importância no dia a dia dos alunos.

No que tange ao contexto didático pelo qual os conteúdos são apresentados, houve um balanço positivo em aspectos gerais. Grande parte das obras traz textos explicativos claros e em linguagem acessível, embora haja diferença no teor dos conteúdos de obra para obra, sendo mais completa em algumas e superficiais em outras. Foi observado também pelos alunos, ainda que sem prejuízo didático na forma como os textos são apresentados, que tem aparecido um maior volume de termos técnicos nos conteúdos de geomorfologia das obras destes últimos anos, estando esta tendência possívelmente associada ao crescimento da importância deste ramo científico nas análises ambientais, levando ao maior uso e maior notoriedade de determinados termos e conceitos que se tornaram frequentes nos estudos de cunho ambiental. 
No mesmo sentido, o emprego de recursos tais como ilustrações, fotos, mapas, gráficos e tabelas associados ao estudo do relevo, tem se tornado cada vez mais presente nas obras, e com crescente qualidade no aspecto elucidativo do que se busca exemplificar. Mantendo a qualidade didática das obras, foi constatado também que a utilização destes recursos visuais não surgem de modo desbaratinado ao longo das páginas, mas em sua grande maioria estão referenciadas e consonantes com as informações apresentadas nos textos.

\section{Considerações finais.}

O modo pelo qual os conteúdos de geomorfologia são trazidos pelos livros didáticos varia de obra para obra, entretanto, percebe-se uma estrutura de apresentação similar entre todas. De modo geral, ainda existem condições específicas que precisam ser aprimoradas, envolvendo a forma como são explicadas as origens, a evolução e a dinâmica das diferentes formas do relevo em associação com as múltiplas escalas espaciais e temporais. Da mesma forma, há ainda uma carência nas abordagens utilizadas pelos livros didáticos em associar os ensino de geomorfologia com as dinâmicas das paisagens integradas a biota, aos solos, ao clima, etc., assim como com os efeitos provocados pelas atividades humanas, dentro de uma realidade reconhecida pelos estudantes.

Não obstante a importância conferida aos livros didáticos como recurso de apoio às aulas e como fonte de consulta para os estudantes, não se pode também desconsiderar a importância da formação docente, sendo de suma importância o domínio do assunto pelos professores de geografia, e a manutenção do permanente hábito de pesquisa em torno do tema, independente dos conteúdos trazidos pelos livros didáticos. No fim, é a associação destes fatores que farão a diferença no ensino de geomorfologia nas escolas.

\section{REFERENCIAS}

ALBUQUERQUE, F. N.; SOBRINHO, J. F. A geomorfologia do semi-árido brasileiro nos livros de geografia do Ensino Médio: Agentes, Processos Morfogenéticos e formas de relevo. In: Homem, Tempo e Espaço, v. 1, p. 01-12, 2007.

ALENCAR, Roberta; NASCIMENTO, Rosemy S.; GUIMARÃES, Gilson B. Geociências no ensino fundamental: ciências ou geografia? Da história da Terra à paisagem local através da geodiversidade da ilha de Santa Catarina. In: Simpósio Nacional de Ensino de Ciências e Tecnologias, 3, 2012, Ponta Grossa. Anais... Ponta Grossa: UEPG, 2012.

BATISTA, Daiane F.; SOUSA, Flávio A. Ensino de geomorfologia nas escolas. In: Congresso de Educação, 2, 2012, Iporá. Anais... Iporá: UEG, 2012. 


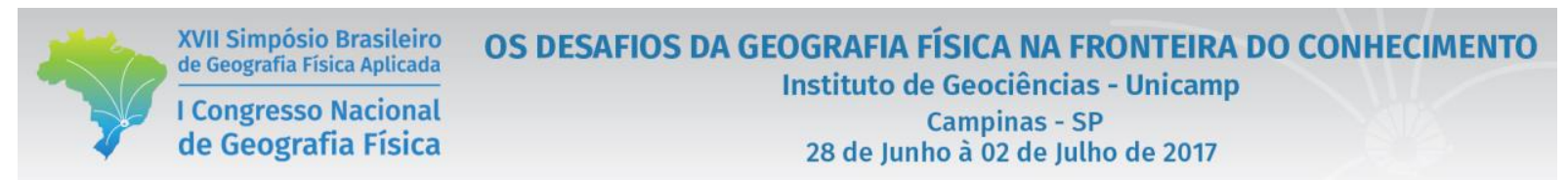

OLIVEIRA, R. M.; AMORIM, R. R.; SANTOS, M. C. F. Geomorfologia no ensino de geografia na educação básica. In: Simpósio Nacional de Geomorfologia, 6, 2006, Goiânia. Anais... Goiânia: UFG, 2006.

OLIVEIRA, Adriana O. S. A.; NUNES, João O. R. Contextos e significados do relevo para o ensino de Geomorfologia. In: Caderno Prudentino de Geografia, n. 31, v. 1, p. 127-147, 2009. 